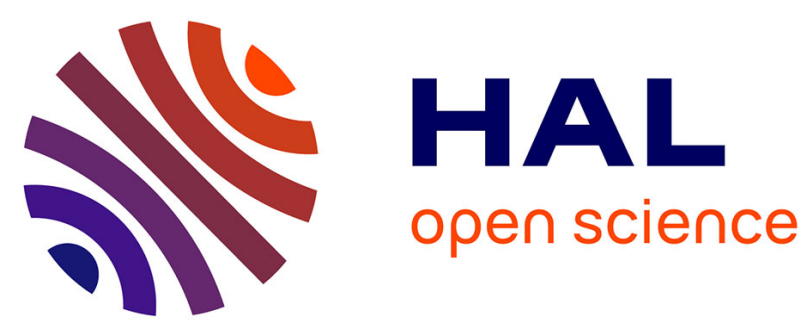

\title{
Experimental Evidence for Unusual Protonation of Tetraethyl p-tert-Butylcalix[4]arene Tetraacetate and the Most Probable Structure of the Resulting Complex
}

\author{
Jaroslav Kriz, Jiri Dybal, Emanuel Makrlik, Petr Vanura
}

\section{- To cite this version:}

Jaroslav Kriz, Jiri Dybal, Emanuel Makrlik, Petr Vanura. Experimental Evidence for Unusual Protonation of Tetraethyl p-tert-Butylcalix[4]arene Tetraacetate and the Most Probable Structure of the Resulting Complex. Supramolecular Chemistry, 2009, 20 (04), pp.387-395. 10.1080/10610270701278251 . hal-00513507

\section{HAL Id: hal-00513507 \\ https://hal.science/hal-00513507}

Submitted on 1 Sep 2010

HAL is a multi-disciplinary open access archive for the deposit and dissemination of scientific research documents, whether they are published or not. The documents may come from teaching and research institutions in France or abroad, or from public or private research centers.
L'archive ouverte pluridisciplinaire HAL, est destinée au dépôt et à la diffusion de documents scientifiques de niveau recherche, publiés ou non, émanant des établissements d'enseignement et de recherche français ou étrangers, des laboratoires publics ou privés. 


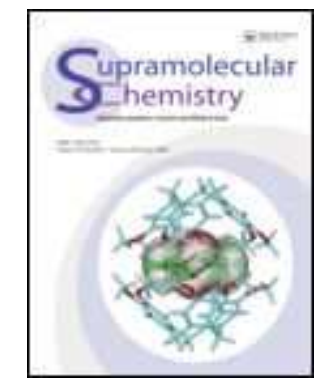

\section{Experimental Evidence for Unusual Protonation of Tetraethyl \\ p-tert-Butylcalix [4]arene Tetraacetate and the Most Probable Structure of the Resulting Complex}

\begin{tabular}{|c|c|}
\hline Journal: & Supramolecular Chemistry \\
\hline Manuscript ID: & GSCH-2006-0107.R2 \\
\hline Manuscript Type: & Full Paper \\
\hline $\begin{array}{r}\text { Date Submitted by the } \\
\text { Author: }\end{array}$ & 06-Feb-2007 \\
\hline Complete List of Authors: & $\begin{array}{l}\text { Kriz, Jaroslav; Institute of Macromolecular Chemistry, Structure } \\
\text { Analysis } \\
\text { Dybal, Jiri; Institute of Macromolecular Chemistry, Structure } \\
\text { Analysis } \\
\text { Makrlik, Emanuel; University of West Bohemia, Faculty of Sciences } \\
\text { Vanura, Petr; Prague Institute of Chemical Technology }\end{array}$ \\
\hline Keywords: & Calixarene complex, protonation, NMR, DFT \\
\hline
\end{tabular}

\section{今scholarONE \\ Manuscript Central}



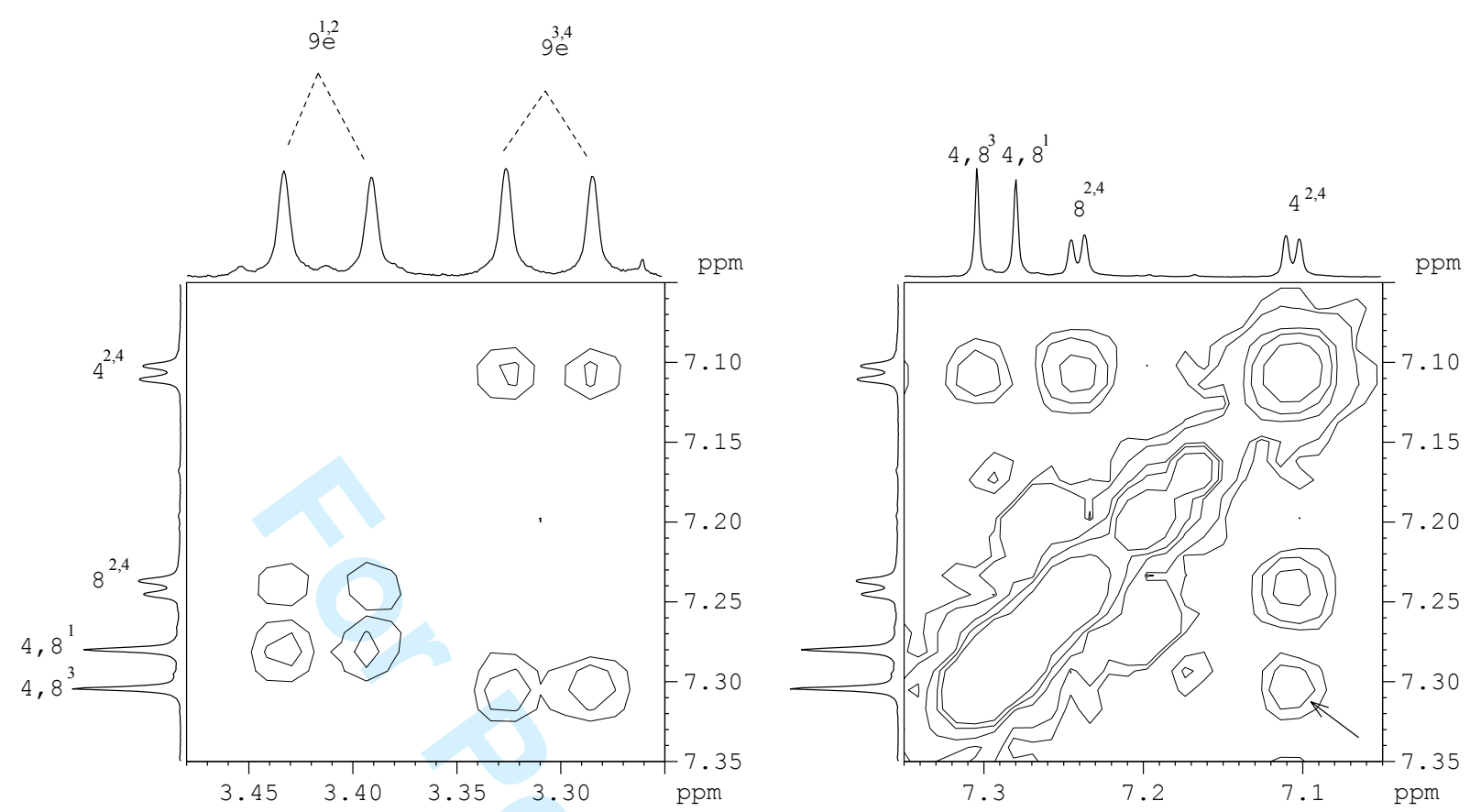

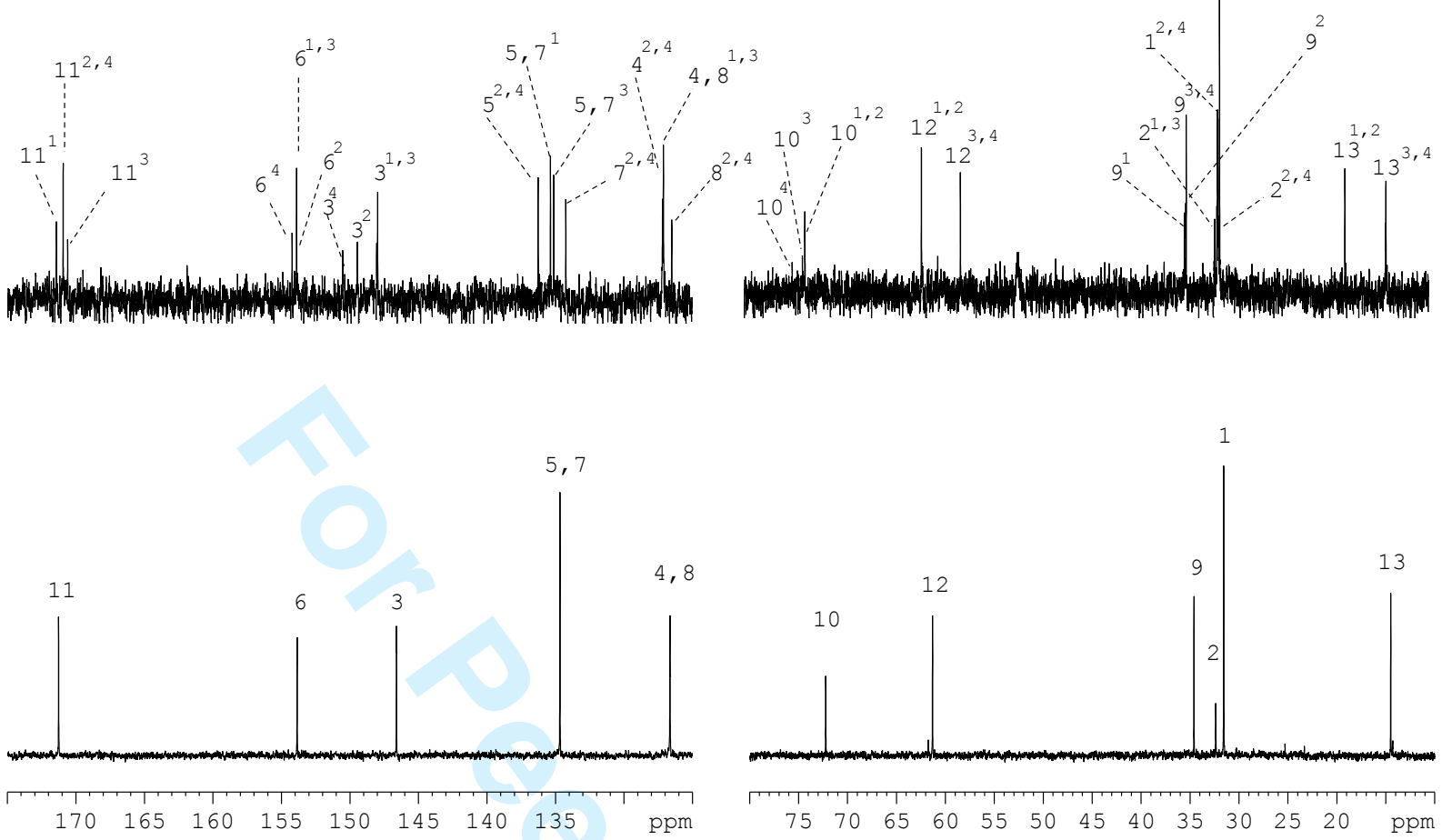


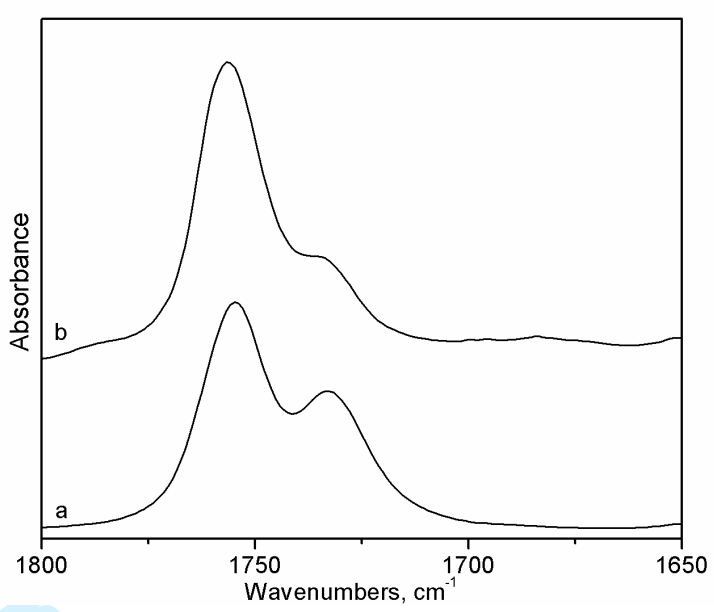



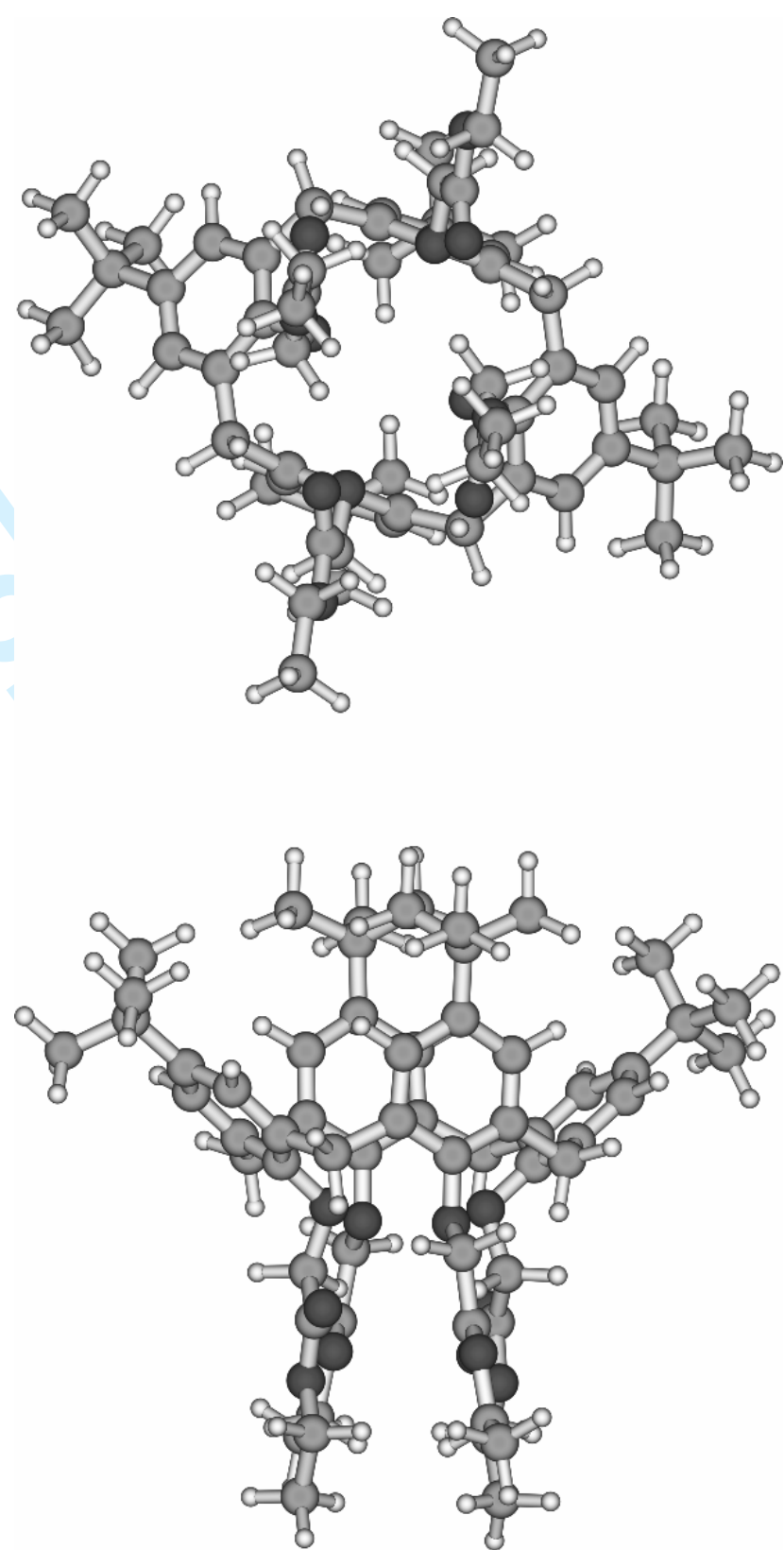

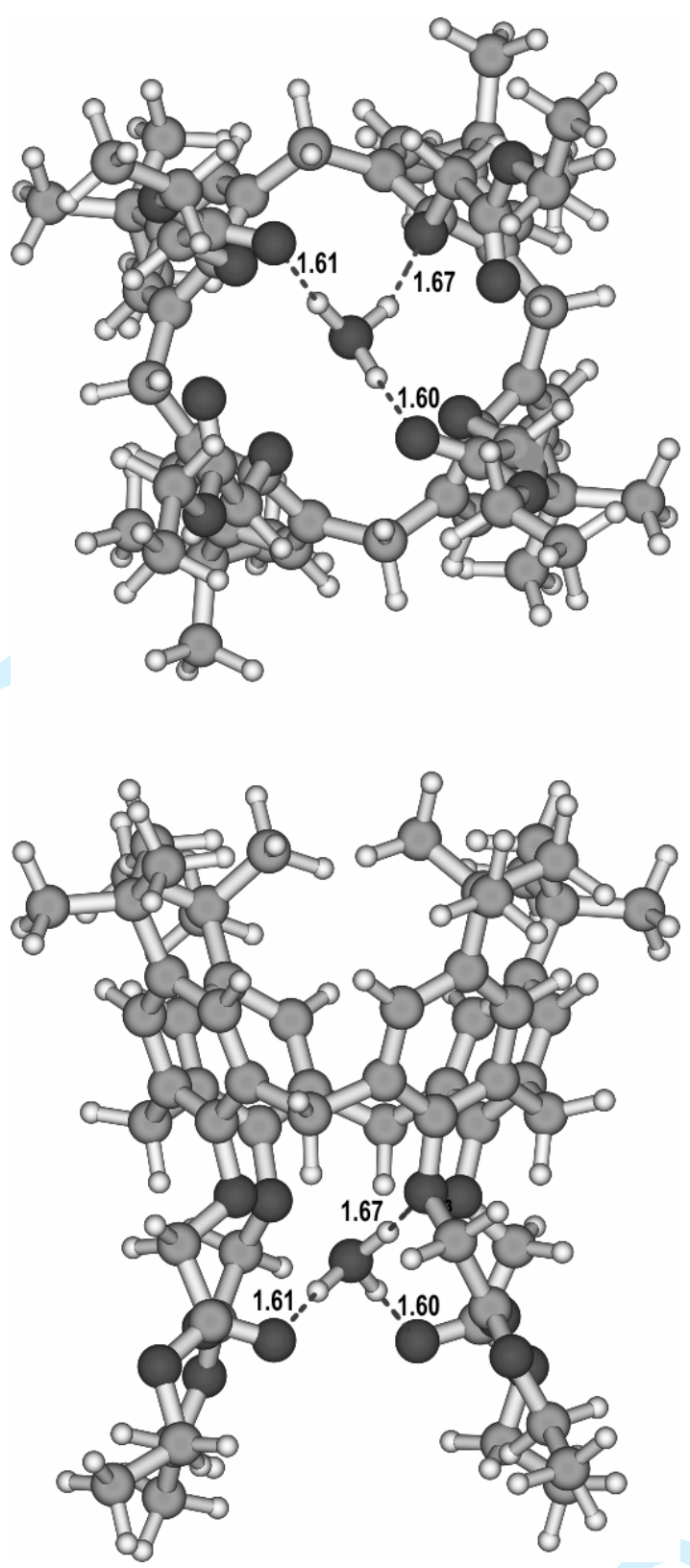

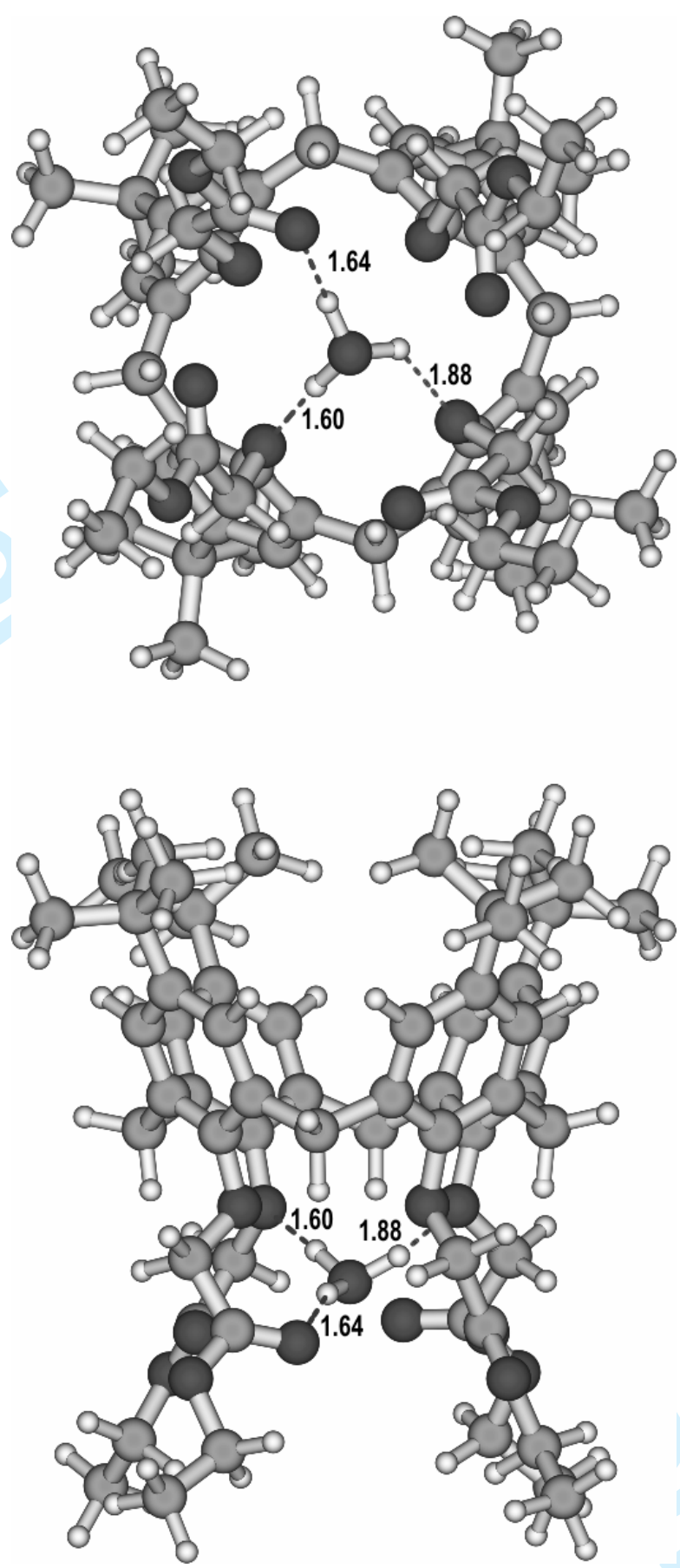

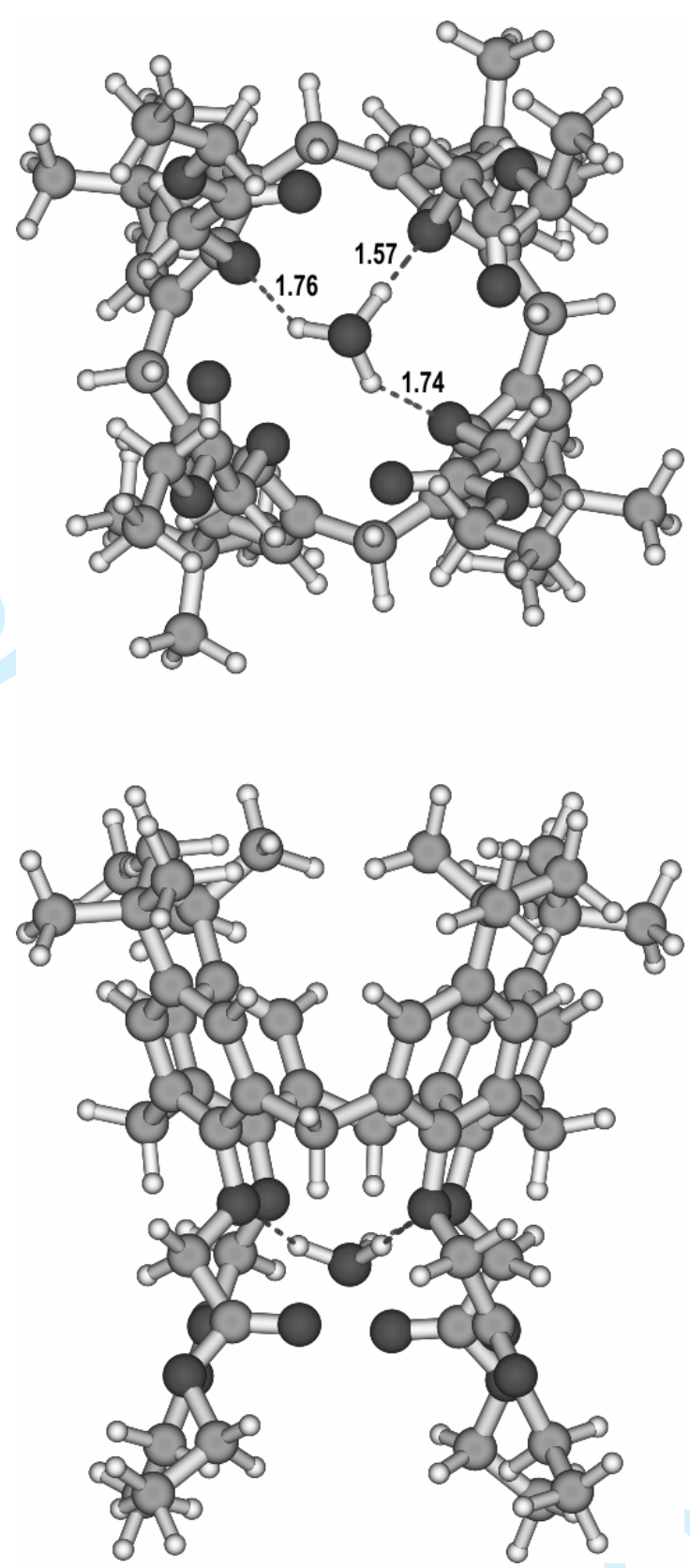


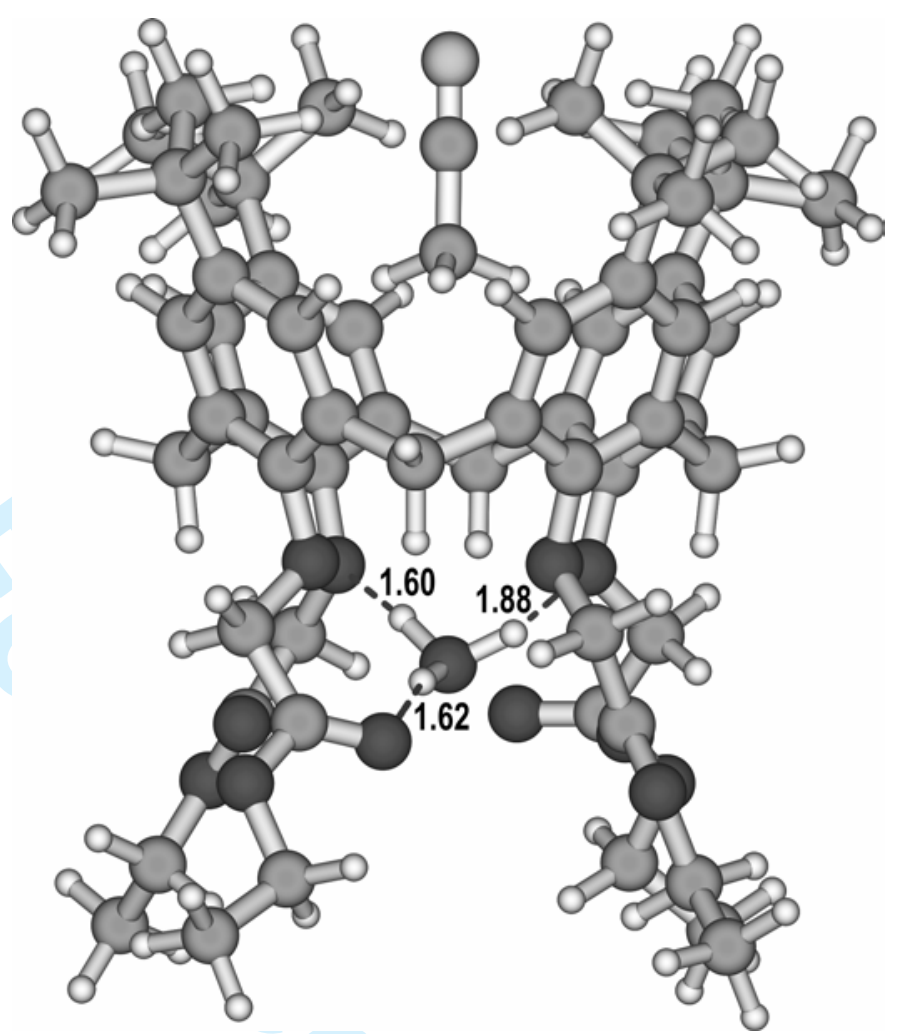




\title{
Experimental Evidence for Unusual Protonation of Tetraethyl p-tert-Butylcalix[4]arene Tetraacetate and the Most Probable Structure of the Resulting Complex
}

JAROSLAV KŘÍŽ ${ }^{*}$, JIŘÍ DYBAL $^{a}$, EMANUEL MAKRLÍK $^{b}$, and PETR VAŇURA ${ }^{c}$

\author{
${ }^{a}$ Institute of Macromolecular Chemistry, Academy of Sciences of the Czech Republic, \\ Heyrovského sq.2, 16206 Prague, Czech Republic.E-mail: kriz@imc.cas.cz \\ ${ }^{b}$ Faculty of Applied Sciences, University of West Bohemia, Husova 11, 30614 Pilsen, Czech \\ Republic. \\ ${ }^{c}$ Prague Institute of Chemical Technology, Technická 5, 16628 Prague, Czech Republic.
}

Using ${ }^{1} \mathrm{H}$ and ${ }^{13} \mathrm{C}$ NMR, FT IR spectroscopy together with quantum mechanical DFT calculations, we show that tetraethyl p-tert-butylcalix[4]arene tetraacetate (1) forms a stable equimolecular complex with proton in the form of hydroxonium ion in acetonitrile- $d_{3}$. Protons for this complex were offered by hydrogen bis(1,2-dicarbollyl) cobaltate (HDCC) and converted to hydroxonium ions by traces of water. The complex $1 \cdot \mathrm{H}_{3} \mathrm{O}^{+}$adopts a slightly asymmetric conformation, which is distinctly more cone-like than ligand 1. According to spectral evidence, the hydroxonium ion $\mathrm{H}_{3} \mathrm{O}^{+}$is bound mainly to three of the phenoxy oxygen atoms of 1 by strong hydrogen bonds leaving the ester carbonyl groups, which are the usual coordination site for metal cations, free. Theoretical DFT calculations support the bonding to phenoxy oxygen atoms but slightly prefer a structure with one of the carbonyls being involved in the coordination.

Keywords: Calixarene complex; protonation; NMR; DFT 


\section{INTRODUCTION}

Calixarene-based molecules have received intense attention in the last years as selective binders and carriers, analytical sensors, catalysts and model structures for biomimetic studies.[1,2] Many studies have focused on the binding ability of calixarene derivatives with carbonyl or analogous groups at their lower rims toward metal ions, predominantly alkali and alkaline-earth, but also transition and heavy metal cations.[3-11] In our previous study [12], we have shown that a calixarene carrying dimethylthioamide groups on its lower rim, namely p-tert-butylcalix[4]arene-tetrakis(N,N-dimethylthioacetamide), binds a hydroxonium ion $\mathrm{H}_{3} \mathrm{O}^{+}$in an equimolecular and very stable complex. In that case, thioamide groups were the chief binding groups although phenoxy oxygen atoms were also involved in the binding. The structure of the complex was in many features similar to those observed with coordinated metallic cations. Considering the rich variety of functionalized calixarenes already known, it is of both theoretical and practical interest if other calixarenes with similar structure behave in an analogous way. In the present work, we examine protonation of tetraethyl p-tertbutylcalix[4]arene tetraacetate (abbrev. 1) in acetonitrile- $d_{3}$. As shown, 1 binds hydroxonium ions but in a distinctly different and somewhat surprising way.

Like in our previous studies, hydrogen bis(1,2-dicarbollyl) cobaltate (HDCC)[13] was used as a source of protons, which were converted to hydroxonium ions $\mathrm{H}_{3} \mathrm{O}^{+}$by a 2.5 $\mathrm{mol} / \mathrm{mol}$ excess of water $[14,15]$. Combining NMR and infrared spectral evidence with DFT quantum mechanical calculations, we suggest the most probable structure of protonated calixarene $\mathbf{1}$.

\section{RESULTS AND DISCUSSION}

Interaction between the hydroxonium ions $\mathrm{H}_{3} \mathrm{O}^{+}$, provided by hydrogen bis(1,2dicarbollylide) cobaltate (HDCC) with $2.5 \mathrm{~mol} / \mathrm{mol}$ excess of water, and tetraethyl $p$-tert- 
butylcalix[4]arene tetraacetate (1) shown in Figure 1 was studied in acetonitrile- $d_{3}$ at $25{ }^{0} \mathrm{C}$. HDCC has been shown to be fully ionized in media with dielectric constants higher than 30 such as nitrobenzene or acetonitrile [16, 17]. Being solid at normal temperature and well soluble in organic solvents, this superacid is a convenient source of free protons. In the presence of traces of water, protons are readily converted to variously hydrated hydroxonium ions $\mathrm{H}_{3} \mathrm{O}^{+}[16]$.

In acetonitrile- $d_{3}$, the first signs of coordination can be observed within minutes, but the system evolves further to a relative equilibrium during next 6 to 12 hours. In the following, the results obtained 12 or more hours after mixing are presented.

NMR spectra. In Figure $2,{ }^{1} \mathrm{H}$ NMR spectra of $\mathbf{1}$ and its equilibrium 1:1 mixture with HDCC are compared. The signal assignment, obtained by using 2D COSY, COSY-LR and NOESY spectra, corresponds to Scheme 1, where the numbering of protons is the same as that of the attached carbon atoms; the upper index refers to the respective aryl unit in the four-member ring and will be discussed below.

The spectra of 1-HDCC mixtures with the HDCC/1 ratio lower than 1.0 are additive superpositions of those shown in Figure 1. The respective spectra obtained with larger than equimolar ratios up to $2.0 \mathrm{~mol} / \mathrm{mol}$ are virtually identical with that corresponding to 1.0 mol/mol. Clearly, $\mathrm{H}_{3} \mathrm{O}^{+}$forms an equimolar complex $\mathbf{1} \cdot \mathrm{H}_{3} \mathrm{O}^{+}$with a very high equilibrium constant, the value of which is beyond the possibilities of exact determination by NMR. At HDCC/ $\mathbf{1}$ ratio lower than 1.0, the exchange between free and the complexed $\mathbf{1}$ is very slow even at the NMR time-scale. This can be documented by the fact that these spectra are superpositions of those of the free and complexed $\mathbf{1}$. No detectable shift of free $\mathbf{1}$ signals and no measurable dependence of their $T_{1 \rho}$ value on the intensity of spin-lock field can be observed. It means that the correlation time of exchange $\tau_{\mathrm{ex}}$ must be of the order at least $10 \mathrm{~s}$. 
We can thus conclude that the complex $\mathbf{1} \cdot \mathrm{H}_{3} \mathrm{O}^{+}$is formed very slowly but exhibits high stability.

The spectrum of $\mathbf{1}$ in Figure 2 contains only one signal or multiplet for each type of proton or group in the calixarene molecule (with exception of protons 12); even protons 4 and 8 are equivalent. All this seemingly points to $C_{4}$ symmetry. However, it is well documented that calix[4]arene derivatives adopt a pinched cone conformation with $\mathrm{C}_{2 \mathrm{v}}$ symmetry of the macrocycle (neglecting conformations of the lower rim substituents that may further decrease the actual symmetry) rather than the effective $\mathrm{C}_{4}$ symmetry that can be deduced from $1 \mathrm{H}$ NMR spectra $[18,19]$. The average spectral shape is caused by an interconversion between two identical structures (pinched cone) which is fast on the NMR time scale at normal temperature [19]. This spectral behavior is quite analogous to that of the dimethylthioamide derivative of the same calixarene. [12]

In contrast to it, the spectrum of the complex $1 \cdot \mathrm{H}_{3} \mathrm{O}^{+}$shows a much lower symmetry. As revealed by ${ }^{1} \mathrm{H}$ DQF COSY spectrum (not shown), the signals $9_{\mathrm{e}}$ and $9_{\mathrm{a}}$ (the indexes meaning equatorial and axial protons) are doubled and all others tripled or, in the case of 12 , quadrupled in the complex $\mathbf{1} \cdot \mathrm{H}_{3} \mathrm{O}^{+}$. In two of the four aryl moieties, protons 4 and 8 become nonequivalent in the complex under study.

Some light on the structure can be shed by examining vicinity in space $(<0.4 \mathrm{~nm})$ using ${ }^{1} \mathrm{H}$ NOESY spectrum. Two sections of it containing nontrivial cross-peaks are shown in Figure 3. In the left section, one type of $9_{\mathrm{e}}$ is near to protons 8 of one type of aryl and to 4 or 8 of another type; another $9_{\mathrm{e}}$ is near to protons 4 of one type aryl and to 4 or 8 of the third type. In the second section, one cross-peak (between 4 and 8) is trivial showing only that these protons belong to the same aryl but that marked by an arrow reveals vicinity between protons 4 of one aryl and 8 of the neighboring aryl; the cross-peak between 8 and 4 of the second aryl type is probably present but poorly resolved. 
Numbering in the upper index the aromatic moieties in the calixarene ring e.g. in the clockwise direction and denoting the magnetic equivalence and nonequivalence by eq. and neq., respectively, then we can see that $\left(9_{\mathrm{e}}{ }^{1}\right.$ eq. $\left.9_{\mathrm{e}}{ }^{2}\right)$ neq. $\left(9_{\mathrm{e}}{ }^{3}\right.$ eq. $\left.9_{\mathrm{e}}^{4}\right)$ entails $\left(4^{1}\right.$ eq. $\left.8^{1}\right)$ neq. $\left(4^{3}\right.$ eq. $\left.8^{3}\right)$ neq. $\left[\left(4^{2}\right.\right.$ neq. $\left.8^{2}\right)$ eq. $\left(4^{4}\right.$ neq. $\left.\left.8^{4}\right)\right]$. Exactly this is found in the pattern of the spectrum indicating thus a lowered symmetry in the calixarene part of the molecule to a mere mirror plane going through the axes of the $\mathrm{Ar}^{1}$ and $\mathrm{Ar}^{3}$ moieties. Such an arrangement can occur if the apexes of three of the four aryl moieties (e.g. moieties 1,2 and 3) are fixed in their positions by coordination bonds with $\mathrm{H}_{3} \mathrm{O}^{+}$. This idea is fortified by the fact that an analogous pattern can be seen in all other signals (even protons 1 give three signals with intensities $1: 1: 2)$

A remarkable feature of the spectrum is the nonequivalence of geminal protons in two of the four $\mathrm{CH}_{2}$ groups 10 (the right assignment being proved by COSY and HSQC). Normally, $\mathrm{O}-\mathrm{CH}_{2}-\mathrm{COO}$ - group should have sufficient motional freedom to average the magnetic shielding of its two protons as observed in free 1. Strong nonequivalence of protons $10_{\mathrm{a}}^{3,4}$ and $10 \mathrm{e}^{3,4}$ indicates hindered or asymmetric rotation of the corresponding methylenes, which must be caused by a relative immobilization of some of the vicinal groups (ester carbonyl or Oaryl) in the $\mathbf{1} \cdot \mathrm{H}_{3} \mathrm{O}^{+}$complex. At the same time, the whole calixarene complex $\mathbf{1} \cdot \mathrm{H}_{3} \mathrm{O}^{+}$must be obviously somewhat skewed out of symmetry or, alternatively, the averaging of its asymmetric conformations must be arrested.

${ }^{13} \mathrm{C}$ NMR spectra of $\mathbf{1}$ and its $\mathbf{1} \cdot \mathrm{H}_{3} \mathrm{O}^{+}$complex are shown in Figure 4 . The signal assignment was done using 2D HSQC and HMBC spectra. Like in ${ }^{1} \mathrm{H}$ NMR spectra, the ${ }^{13} \mathrm{C}$ NMR spectrum of $\mathbf{1}$ itself has only one signal for each carbon type and shows magnetic equivalence of carbons 4,8 or 5,7 suggesting thus again a $\mathrm{C}_{4}$ symmetry of the molecule 
or a fast averaging of the structure to the same effect. However, the signals of the $1 \cdot \mathrm{H}_{3} \mathrm{O}^{+}$ complex are richly resolved again. As it can be seen, the pattern of resolution of the signals of individual carbon types is very like those of proton signals, the integral intensities of signals of individual groups being in the ratio 1:1:2 (atoms 1, 3, 4, 6, 8, 9, 10, 11) , 1:1:1:1 (atoms 2, 5,7 ) or 2:2 (atoms 12,13). Further, the shifts of two of the four atoms 12 and 13, i.e. of the ethyl groups attached to two ester carbonyls, are the most apparent. Besides, relatively strong shifts of atoms 10 (both protons and carbons) are found. On the other hand, any strong signal shifts of carbons 11 are not observed. This fact surprisingly indicates that the ester carbonyls of $\mathbf{1}$ are not strongly involved in coordination of $\mathrm{H}_{3} \mathrm{O}^{+}$.

Infrared spectra. The lack of any appreciable shift of the carbonyl signals in ${ }^{13} \mathrm{C}$ NMR is a serious indication but not sufficient proof that the carbonyls are not involved in coordination with $\mathrm{H}_{3} \mathrm{O}^{+}$. Therefore, we turned to FT IR spectra, a technique in many ways complementary to NMR. Strong hydrogen bonds or various coordination bonds are known to produce strong shifts of the characteristic $\mathrm{C}=\mathrm{O}$ stretching vibration.

In Figure 5, the region of carbonyl stretching vibrations is depicted. In the bottom spectrum, one can see the characteristic splitting of the band into in-phase (right) and out-ofphase (left) vibrations due to a symmetric alignment of the carbonyl groups in the parent calixarene. In the upper spectrum of the equimolar mixture of 1 with HDCC, the shape of the doublet is remarkably similar, the only difference being a relative intensity increase of the left part of the mentioned doublet. In our view, this difference can be interpreted as a slight disturbance of the symmetry of the alignment of the carbonyl groups as a consequence of the proved complexation of $\mathrm{H}_{3} \mathrm{O}^{+}$with $\mathbf{1}$. However, it is necessary to emphasize that there is definitely no shift in carbonyl vibrations due to the considered complexation, which excludes any strong hydrogen bond of $\mathrm{H}_{3} \mathrm{O}^{+}$to the ester carbonyl groups. This result is in accordance with ${ }^{13} \mathrm{C}$ NMR observations. Taking into account the shifts of the aromatic carbons in ${ }^{13} \mathrm{C}$ 
NMR, the most probable structure of the $1 \cdot \mathrm{H}_{3} \mathrm{O}^{+}$complex is that with $\mathrm{H}_{3} \mathrm{O}^{+}$bound by strong hydrogen bonds to the phenoxy oxygen atoms of $\mathbf{1}$.

Quantum mechanical calculations. The evidence both from NMR and IR spectra that the ester carbonyls of $\mathbf{1}$ are not strongly involved in coordination of $\mathrm{H}_{3} \mathrm{O}^{+}$made us turn to quantum calculations. On the B3LYP level of density functional theory (DFT) with the 6$31 \mathrm{G}(\mathrm{d})$ basis set[18], the calculations of molecular geometry and even some of the spectral characteristics attain a degree of reliability and precision comparable with that of experimental results. The calculations were performed in vacuo as no reliable correction for the influence of the medium exists at this level of precision.

First, we optimized the geometry of uncoordinated ligand 1 using the corresponding Xray data [5]. The result of unrestricted optimization of the structure is shown in Figure 6. The predicted optimal structure has $\mathrm{C}_{2}$ rather than $\mathrm{C}_{4}$ symmetry in the aryl part, two opposite aryl rings being markedly more parallel than the other two. As already discussed above, fast exchange between two alternately flattened structures (a kind of "breathing" of the structure), leads to an averaged $\mathrm{C}_{4}$-symmetrical image in NMR.

When adding the $\mathrm{H}_{3} \mathrm{O}^{+}$cation to the optimized structure of $\mathbf{1}$, we get (after a new unrestricted optimization including the whole calixarene molecule) first structure A shown in Figure 7, where the ion $\mathrm{H}_{3} \mathrm{O}^{+}$is bound by three strong $\mathrm{H}$-bonds to two of the four carbonyl oxygen atoms and one of the four phenoxy oxygen atoms. This is, however, only a local minimum as it can be seen by comparison of energies in Table 1.

By a slight manipulation of the $\mathrm{H}_{3} \mathrm{O}^{+}$ion position and renewed unrestricted geometry optimization, we arrive at a deeper energy minimum with the corresponding structure B depicted in Figure 8. Here, $\mathrm{H}_{3} \mathrm{O}^{+}$is bound to only one of the carbonyl oxygen atoms and to two phenoxy oxygens of different aryl moieties. According to the energy given in Table 1 structure B should correspond to the global minimum. 
Table 1: Calculated energies of the lowest-energy optimal structures (relative to global minimum) of the $\mathbf{1} \cdot \mathrm{H}_{3} \mathrm{O}^{+}$and $\mathrm{CH}_{3} \mathrm{CN} \cdot \mathbf{1} \cdot \mathrm{H}_{3} \mathrm{O}^{+}$complexes.

\begin{tabular}{ccc}
\hline guest & Structure & $\begin{array}{c}\Delta \mathrm{E}_{\mathrm{el}} \\
\mathrm{kJ} / \mathrm{mol}\end{array}$ \\
\hline none & $\mathrm{A}$ & +18.20 \\
& $\mathrm{~B}$ & 0 \\
$\mathrm{CH}_{3} \mathrm{CN}$ & $\mathrm{C}$ & +4.39 \\
& $\mathrm{~A}^{\prime}$ & +16.53 \\
& $\mathrm{~B}^{\prime}$ & 0 \\
& $\mathrm{C}^{\prime}$ & +6.99 \\
\hline
\end{tabular}

When exploring further possible orientations and positions of $\mathrm{H}_{3} \mathrm{O}^{+}$, we found another local or almost global - energy minimum in structure $\mathrm{C}$ illustrated in Figure 9. Here, $\mathrm{H}_{3} \mathrm{O}^{+}$is bound by strong $\mathrm{H}$-bonds to three of the four phenoxy oxygen atoms. As given in Table 1, the corresponding energy is predicted to be about $1 \mathrm{kcal} / \mathrm{mol}$ higher than that corresponding to structure B. One has to admit that this difference is in the limits of precision of the calculation, in particular for such a large molecule and without taking correction to the influence of a rather polar medium. It is thus entirely possible that structure $\mathrm{C}$ corresponds in reality to the global energy minimum.

Further exploration of other possible positions and orientations of $\mathrm{H}_{3} \mathrm{O}^{+}$did not lead to any other energy minima. We thus have to compare structures $\mathrm{A}, \mathrm{B}$ and $\mathrm{C}$ with our experimental results. Structure A appears to be excluded on energy grounds as a final state of the complex but it probably corresponds to a transition state of its formation. Structure B, although predicted to be most stable, does not correspond to experimental results: a strong Hbond even to one of the carbonyls should offer a strongly shifted carbonyl signal both in ${ }^{13} \mathrm{C}$ NMR and IR. Contrary to this, structure $C$ bears quite a number of features compatible with experimental results: (i) $\mathrm{H}_{3} \mathrm{O}^{+}$is bonded to three of the four phenoxy oxygen atoms, affecting thus the carbonyl groups only indirectly (cf. only small shift of $\mathrm{C}=\mathrm{O}$ in ${ }^{13} \mathrm{C}$ NMR, no shift in IR); (ii) bonding to O-aryl shifts the electron density in particular in atoms 3 and 6 (cf. large shifts of part of signals 3 and 6 in ${ }^{13} \mathrm{C} \mathrm{NMR}$ ); (iii) bonding to the electron lone pairs of O-Ar 
hinders rotation of the vicinal $\mathrm{CH}_{2}$ group and forms an asymmetric environment for it (cf. nonequivalence of axial and equatorial protons 10 in part of ${ }^{1} \mathrm{H}$ signal); (iv) bonding to three phenoxy oxygens creates the mirror symmetry in the calixarene aryl part (cf. the pattern of nonequivalence of protons 4,8 , and 9 in ${ }^{1} \mathrm{H}$ NMR discussed above).

There presumably are minor differences between structure $\mathrm{C}$ and the actual structure of the complex $\mathbf{1} \cdot \mathrm{H}_{3} \mathrm{O}^{+}$. For instance, there are large shifts of signals $12^{1}$ and $13^{1}$ in ${ }^{1} \mathrm{H} \mathrm{NMR}$ spectrum, which are not justified by the predicted structure. However, this discrepancy is not of major importance as the ester ethyl groups are on the outer rim of the complex under study and thus most influenced by the medium. Therefore, we suggest that the calculated structure C is probably very near to the actual stable structure of the $1 \cdot \mathrm{H}_{3} \mathrm{O}^{+}$complex.

Up to now, we assumed that acetonitrile- $d_{3}$ was an inert medium with mere dielectric and nonspecific solvatation interactions with the reactants. However, there is evidence that Osubstituted calix[4]arenes can act as hosts for acetonitrile inclusion [21-32]. Nevertheless, such host-guest interaction does not appear to interfere with a complexation of ions by the polar groups at the lower rim. In some cases, it apparently even facilitates such an interaction. In the case of calix[4]arene tetra-acetamide, ${ }^{1} \mathrm{H}$ NMR shows that acetonitrile inclusion does not prevent complexation with $\mathrm{Na}^{+}$in solution [30]. This can be understood in view of the fact that the calixarene cavity has the same conformation in the inclusion compound and the $\mathrm{Na}^{+}$ complex, according to X-ray data [30]. The same situation can be expected in our case.

Nonetheless, we optimized the geometries of the $\mathrm{CH}_{3} \mathrm{CN} \cdot 1$ complex and its complexes with $\mathrm{H}_{3} \mathrm{O}^{+}$. In all the structures obtained, the methyl group of $\mathrm{CH}_{3} \mathrm{CN}$ is centrally immersed in the calixarene cavity which adopts a symmetric conformation, in agreement with X-ray data [21]. The binding energy of $\mathrm{CH}_{3} \mathrm{CN}$ is $5.61 \mathrm{~kJ} / \mathrm{mol}$, i.e. acetonitrile is only weekly bound. When inspecting the possible binding of $\mathrm{H}_{3} \mathrm{O}^{+}$to $\mathrm{CH}_{3} \mathrm{CN} \cdot \mathbf{1}$ complex, we obtained three lowest-energy structures A', B' and C' quite analogous to those obtained above, i.e. A, B, and 
C. As shown in Table 1 , the respective energy differences of $A^{\prime}$ and $C^{\prime}$ from the global minimum $\mathrm{B}^{\prime}$ are again quite analogous to the former case. The optimized structure $\mathrm{B}^{\prime}$ is shown in Figure 10. Quite analogously to $\mathrm{B}, \mathrm{H}_{3} \mathrm{O}^{+}$is bound by strong hydrogen bonds to two aryloxy atoms and one of the ester carbonyls. In the energetically almost equivalent structure C', the ion is bound to three of the four aryloxy atoms. Acetonitrile inclusion thus does not appear to influence $\mathrm{H}_{3} \mathrm{O}^{+}$binding in a perceptible way.

In summary, the structure of the complex $\mathbf{1} \cdot \mathrm{H}_{3} \mathrm{O}^{+}$in acetonitrile- $d_{3}$ solution was examined by a combination of ${ }^{1} \mathrm{H}$ and ${ }^{13} \mathrm{C}$ NMR, infrared spectra and quantum mechanical DFT calculations. According to these methods, $\mathrm{H}_{3} \mathrm{O}^{+}$is not primarily bound to the carbonyl groups, but to three of the four phenoxy oxygen atoms by strong hydrogen bonds. The calixarene part of the considered complex $\mathbf{1} \cdot \mathrm{H}_{3} \mathrm{O}^{+}$has a plane of symmetry going through one of these $\mathrm{H}$ bonds and the axes of the adjacent and opposite aromatic moiety. The form of the calixarene cup of the $\mathbf{1} \cdot \mathrm{H}_{3} \mathrm{O}^{+}$complex is not much distorted relative to free ligand $\mathbf{1}$. Due to the strong $\mathrm{H}$-bonds and steric hindrances caused by the bound $\mathrm{H}_{3} \mathrm{O}^{+}$ion, two of the four $\mathrm{O}-\mathrm{CH}_{2}$ groups (O is phenoxy oxygen) have hindered rotation in an asymmetric environment.

There is an interesting difference between the just described type of $\mathrm{H}_{3} \mathrm{O}^{+}$bonding to $\mathbf{1}$ and that found [12] in the dimethylthioamide analogue of $\mathbf{1}$ where the ion is strongly bound to the $\mathrm{C}=\mathrm{S}$ groups. Also, the dynamics of $\mathrm{H}_{3} \mathrm{O}^{+}$coordination, exchange and internal motion is much more vivid in the latter case so that the structure of the complex appears to be symmetric in NMR, in sharp contrast to the present case. The cause of these differences is not clear considering that the calixarene macrocycle is the same in both cases. Apparently, quite subtle differences in the structure can have a strong effect on the calixarene behavior. This calls for further research in this field.

\section{EXPERIMENTAL}


Materials and samples. Acetonitrile- $d_{5}$ was purchased by Merck, Darmstadt, Germany, and p-tert-butylcalix[4]arene tetraacetate (1) were purchased from Novachem Pty Ltd., Australia. Both substances were used as obtained. Preparation of hydrogen bis(1,2-dicarbollyl) cobaltate (HDCC) was described in Ref. [12]. For NMR samples, $1 \times 10^{-5}$ mol of $\mathbf{1}$ was dissolved in a mixture of appropriate amounts of acetonitril- $d_{3}$ and $0.001 \mathrm{~mol} / \mathrm{L}$ solution of HDCC in the same solvent.

NMR spectra. ${ }^{1} \mathrm{H}$ and ${ }^{13} \mathrm{C}$ NMR spectra were measured in a quadrature detection mode at 300.13 and $75.45 \mathrm{MHz}$, respectively, with an upgraded Bruker Avance DPX300 spectrometer. 32 and 64 kpoints were carried out for ${ }^{1} \mathrm{H}$ and ${ }^{13} \mathrm{C}$ NMR collecting 64 and 25000 or more scans, respectively. ${ }^{13} \mathrm{C}$ NMR measurements were performed in an inverse-gated (NOE uninfluenced) mode, with a $\pi / 6$ pulse and $10.8 \mathrm{~s}$ repetition time; exponential weighting $(\mathrm{lb}=1$ $\mathrm{Hz}$ ) was used before Fourier transform. In homonuclear 2D ${ }^{1} \mathrm{H}$ spectra (COSY, LR-COSY, DQF-COSY, NOESY) and heteronuclear ${ }^{1} \mathrm{H}-{ }^{13} \mathrm{C} 2 \mathrm{D}$ (HSQC and HMBC), 1028 points in F2 and 256 increments in $\mathrm{F} 1$ dimensions were measured using a $\mathrm{z}$-gradient inverse-detection probe.

Infrared spectra. FT IR spectra of the acetonitrile- $d_{3}$ solutions were measured at ambient temperature with a Bruker IFS-55 FTIR spectrometer using cells with $\mathrm{BaF}_{2}$ windows. The spectra were corrected for absorption of the solvent and $\mathrm{H}_{2} \mathrm{O}$ vapors.

Quantum mechanical calculations. Ab initio molecular orbital calculations were performed using the GAUSSIAN 03 suite of programs [16]. Molecular geometry was fully optimized at the B3LYP level of density functional theory (DFT) with the 6-31G(d) basis set. The optimization was unrestrained. Several local configurations near the achieved energy minimum were examined. As the renewed optimizations converged to the same molecular geometry, we believe the achieved energy minimum to be the global one. 
Acknowledgements. This work was supported by the Academy of Sciences of the Czech Republic, Project T400500402, and the Czech Ministry of Education, Youth and Sports, Projects MSM 4977751303 and MSM 6046137307.

\section{References}

[1] Gutsche, C. D. Calixarenes Revisited. The Royal Society of Chemistry, Cambridge, 1998.

[2] Böhmer, V. Angew. Chem., Int. Ed. Engl. 1995, 34, 713-745.

[3] Arduini, A.; Pochini, A.; Reverberi, S.; Ungaro, R. Tetrahedron 1986, 42, 2089-2100.

[4] Arduini, A.; Ghidini, E.; Pochini, A.; Ungaro, R.; Andreetti, G.D.; Calestani, G.; Ugozzoli, F. J. Inclusion Phenom. 1988, 6, 119-134.

[5] Arnaud-Neu, F.; Collins, E.M.; Deasy, M.; Ferguson, G.; Harris, S.J.; Kaitner, B.; Lough, A.J.; McKervey, M.A.; Marques, E.; Ruhl, B.L.; Schwing-Weil, M.J.; Seward, E.M. J. Am. Chem. Soc. 1989, 111, 8681-8691.

[6] Arnaud-Neu, F.; Barrett, G.; Harris, S.J.; Owens, M.; McKervey, M.A.; SchwingWeil, M.J.; Schwinté, P. Inorg. Chem. 1993, 32, 2644-2650.

[7] Ohto, K.; Murakami, E.; Shinohara, T.; Shiratsuchi, K.; Inoue, K.; Iwasaki, M. Anal. Chim. Acta 1997, 341, 275-283.

[8] Ye, Z.; He, W.; Shi, X.; Zhu, L. J. Coord. Chem. 2001, 54, 105-116.

[9] Danil de Namor, A.F.; Chahine, S.; Kowalska, D.; Castellano, E.E.; Piro, O.E. J. Am. Chem. Soc. 2002, 124, 12824-12836.

[10] Marcos, P. M.; Ascenso, J.R.; Segurado, M.A.P.; Pereira, J.L.C. J. Inclusion Phenom. 2002, 42, 281-288.

[11] Marcos, P.M.; Félix, S.; Ascenso, J.R.; Segurado, M.A.P.; Pereira, J.L.C.; KhazaeliPursa, P.; Hubscher-Bruder, V.; Arnaud-Neu, F. New J.Chem. 2004, 28, 748-755. 
[12] Kř́iž, J.; Dybal, J.; Makrlík, E.; Vaňura, P. Supramolecular Chem. in print

[13] Makrlík, E.; Vaňura, P. Talanta 1985, 32, 423-429.

[14] Křriž, J.; Makrlík, E.; Vaňura, P. Biopolymers 2006, 81, 104-109.

[15] Kříž, J.; Dybal, J.; Makrlík, E. Biopolymers 2006, 82, 536-548.

[16] Škarda, V.; Rais, J.; Kyrš, M. J. Inorg. Nucl. Chem. 1979, 41, 1443

[17] Rais, J.; Selucký, M.; Kyrš, M. J. Inorg. Nucl. Chem. 1976, 38, 1376

[18] Gutsche, C. D. Aldrichimica Acta 1995, 28, 3-9

[19] Čajan, M.; Lhoták, P.; Lang, J.; Dvořáková , H.; Stibor, I.; Koča, J. J. Chem. Soc. Perkin Trans., 2002, 2, 1922-1929

[20] Frisch, M. J.; Trucks, G. W.; Schlegel, H. B.; Scuseria, G. E.; Robb, M. A.; Cheeseman, J. R.; Montgomery, Jr., J. A.; Vreven, T.; Kudin, K. N.; Burant, J. C.; Millam, J. M.; Iyengar, S. S.; Tomasi, J.; Barone, V.; Mennucci, B.; Cossi, M.; Scalmani, G.; Rega, N.; Petersson, G. A.; Nakatsuji, H.; Hada, M.; Ehara, M.; Toyota, K.; Fukuda, R.; Hasegawa, J.; Ishida, M.; Nakajima, T.; Honda, Y.; Kitao, O.; Nakai, H.; Klene, M.; Li, X.; Knox, J. E.; Hratchian, H. P.; Cross, J. B.; Bakken, V.; Adamo, C.; Jaramillo, J.; Gomperts, R.; Stratmann, R. E.; Yazyev, O.; Austin, A. J.; Cammi, R.; Pomelli, C.; Ochterski, J. W.; Ayala, P. Y.; Morokuma, K.; Voth, G. A.; Salvador, P.; Dannenberg, J. J.; Zakrzewski, V. G.; Dapprich, S.; Daniels, A. D.; Strain, M. C.; Farkas, O.; Malick, D. K.; Rabuck, A. D.; Raghavachari, K.; Foresman, J. B.; Ortiz, J. V.; Cui, Q.; Baboul, A. G.; Clifford, S.; Cioslowski, J.; Stefanov, B. B.; Liu, G.; Liashenko, A.; Piskorz, P.; Komaromi, I.; Martin, R. L.; Fox, D. J.; Keith, T.; AlLaham, M. A.; Peng, C. Y.; Nanayakkara, A.; Challacombe, M.; Gill, P. M. W.; Johnson, B.; Chen, W.; Wong, M. W.; Gonzalez, C.; and Pople, J. A.; Gaussian 03, Revision C.02, Gaussian, Inc., Wallingford CT, 2004. 
[21] McKervey, M. A.; Seward, E. M.; Ferguson, G.; Ruhl, B. L. J. Org. Chem. 1986, 51, 3581

[22] Danil de Namor, A. F.; Gil, E; Llosa Tanco, M. A.; Pacheco Tanaka, D. A.; Pulcha Salazar, L. E.; Schulz, R. A.; Wang., J. J. Phys. Chem. 1995, 99, 16776; 1995, 99, 16781 and references therein

[23] Thuery, P; Keller, N; Lance, M; Vigner, JD; Nierlich, M J. Inclusion Phenom. Mol. Recogn. in Chem. 1994, 20, 373

[24] Acho, J. A.; Doerrer, L. H.; Lippard, S. J. Inorg. Chem., 1995, 34, 2542

[25]Zhong, Z.-L.; Chen, Y.-Y.; Lu, X.-R.; Luo, B.-S.; Chen, L.-R. Jiegou Huaxue 1996, 15,5

[26] Kalchenko, O. I.; Lipkowski, J.; Kalchenko, V.I.; Vysotsky, M.A.; Markovsky, L.N. J. Chromatographic Sci. 1998, 36, 269

[27] Charbonnière, L.J.; Balsiger, C.; Schenk, K.J.; Bnzii, J.-C.G. J. Chem. Soc. - Dalton Trans., 1998, 505

[28] Radius, U.; Attner, J. Eur. J. Inorg. Chem. 1999, 12, 2221

[29] Sénèque, O.; Campion, M.; Douziech, B.; Giorgi, M.; Rivière, E.; Journaux, Y., Le Mest, Y., Reinaud, O. Eur. J. Inorg. Chem. 2002, 8, 2007

[30] Moser, A.; Yap, G. P. A.; Detellier, Ch. J. Chem. Soc., Dalton Trans.2002, 428

[31] Maharaj, F.; Craig, D.C.; Scudder, M.L.; Bishop, R.; Kumar, N. J. Inclus. Phenom. and Macrocyclic Chem. 2006, 55, 315

[32] Mohammed-Ziegler, I.; Hamdi, A.; Abidi, R.; Vincens, J. Supramolecular Chem. 2006, 18,219

\section{Captions:}

Figure 1: Structure of 1 with assigned carbon atoms 
Figure 2. ${ }^{1} \mathrm{H}$ NMR spectra of $0.01 \mathrm{~mol} / \mathrm{L} 1$ (below) and its equilibrium 1:1 mixture with HDCC (above) (acetonitrile- $\left.d_{3}, 296 \mathrm{~K}\right)$.

Figure 3. Two sections from ${ }^{1} \mathrm{H}$ NOESY spectrum of the $\mathbf{1} \cdot \mathrm{H}_{3} \mathrm{O}^{+}$complex (acetonitrile- $d_{3}$, 296 K).

Figure 4. ${ }^{13} \mathrm{C}$ NMR spectra of $0.01 \mathrm{~mol} / \mathrm{L} 1$ (below) and its equilibrium 1:1 mixture with HDCC (above) (acetonitrile- $d_{3}, 296 \mathrm{~K}$ ).

Figure 5. Carbonyl stretching region of the infrared spectra of of $0.01 \mathrm{~mol} / \mathrm{L} 1$ (below) and its equilibrium (1:1) mixture with HDCC (above) (acetonitrile- $d_{3}, 296 \mathrm{~K}$ ).

Figure 6. Optimized structure of free ligand 1.

Figure 7. Optimized geometry of the $1 \cdot \mathrm{H}_{3} \mathrm{O}^{+}$complex - structure A.

Figure 8. Optimized geometry of the $\mathbf{1} \cdot \mathrm{H}_{3} \mathrm{O}^{+}$complex - structure $\mathrm{B}$.

Figure 9. Optimized geometry of the $\mathbf{1} \cdot \mathrm{H}_{3} \mathrm{O}^{+}$complex - structure C.

Figure 10: Optimal structure of the $\mathrm{CH}_{3} \mathrm{CN} \cdot 1 \cdot \mathrm{H}_{3} \mathrm{O}^{+}$complex, structure B' 